\title{
The elevated NLR, PLR and PLT may predict the prognosis of patients with colorectal cancer: a systematic review and meta- analysis
}

\author{
Jie Zhang ${ }^{1}$, Hong-Ying Zhang ${ }^{2}$, Jia Li ${ }^{1}$, Xin-Yu Shao ${ }^{3}$ and Chun-Xia Zhang ${ }^{1}$ \\ ${ }^{1}$ Department of Oncology, The First Affiliated Hospital of Dalian Medical University, Dalian 116011, China \\ ${ }^{2}$ Department of Pathology and Forensic Medicine, College of Basic Medical Sciences, Dalian Medical University, Dalian \\ 116044, China \\ ${ }^{3}$ Medical Oncology, The First Affiliated Hospital of Dalian Medical University, Dalian 116000, China \\ Correspondence to: Chun-Xia Zhang, email: qm1210@hotmail.com \\ Keywords: colorectal cancer, neutrophils-to-lymphocytes ratio, platelet-to-lymphocytes ratio, platelet counts, prognosis \\ Received: February 24, $2017 \quad$ Accepted: May 05, $2017 \quad$ Published: June 19, 2017 \\ Copyright: Zhang et al. This is an open-access article distributed under the terms of the Creative Commons Attribution License 3.0 (CC BY \\ $3.0)$, which permits unrestricted use, distribution, and reproduction in any medium, provided the original author and source are credited.
}

\section{ABSTRACT}

\begin{abstract}
Recently, several studies have reported that inflammatory response and elevated platelet counts may be associated with the poor prognosis of colorectal cancer. This meta-analysis was designed to analyze and evaluate the prognostic role of elevated preoperative or pretreatment neutrophils-to-lymphocytes ratio, platelet-tolymphocytes ratio or platelet counts in patients with colorectal cancer. We searched PubMed, EMBASE, Cochrane Library and Web of Science to April, 2016. A total of 23 studies ( $N=11762$ participants) were included for this meta-analysis. Elevated neutrophils-to-lymphocytes ratio have a close relationship with the poor Overall Survival of colorectal cancer with the pooled HR being 1.92 [95\% CI 1.57-2.34; $P<0.00001]$. This meta-analysis indicated that elevated neutrophils-to-lymphocytes ratio, platelet-to-lymphocytes ratio or platelet counts may be a cost-effective and noninvasive serum biomarker for poor prognosis for patients with colorectal cancer.
\end{abstract}

\section{INTRODUCTION}

The colorectal cancer (CRC) is one of the increasingly common malignancies worldwide. According to the report from GLOBOCAN 2012, the incidence rate of $\mathrm{CRC}$ is at the third place becoming one of the most common cancers [1]. The incidence of the disease is $12.3 \%$ in men and $13.1 \%$ in women in Europe [2]. What is more, in North America, CRC is the third most common cause of cancer-related deaths [3]. At present, despite advanced instruments for screening and early detection of CRC, and surgical resection being the optimal option for the patients with colorectal cancer, about twenty percent of cases are found to be metastatic at the time of diagnosis and at least about half of patients die within 5 years after their diagnosis $[4,5]$. Thus, appropriate prognostic markers were needed to predict patients' postoperative prognosis and the survival of patients at high risk of recurrence, and to guide patients to choose additional treatment.

Hopefully, in recent years, several reviews have reported that elevated platelet counts and NLR may be associated with the poor prognosis of gastric cancer, lung cancer, renal cancer and gynecologic malignancies [6-9]. Besides, previous studies have showed that elevated NLR, PLR or PLT) also associated with poor prognosis for esophageal, renal and hepatocellular malignancies [10-14]. Likewise, the association between elevated NLR, PLR or PLT and the survival of colorectal cancer had also been published in some studies [1548]. However, fallaciously, their results still remained inconsistent, with several studies drawing inverse conclusions [19, 22, 30, 49]. Therefore, we designed a meta-analysis based on relevant studies to analyze and evaluate the prognostic role of elevated preoperative or 
pretreatment NLR, PLR or PLT in patients with colorectal cancer.

\section{RESULTS}

\section{Included studies and study characteristics}

After 64 studies were excluded (54 studies for the cut-off value not meeting including criteria, 7 studies for lack of available data, 3 studies for just review), a total of 23 studies ( $N=11762$ participants) were included in this meta-analysis, of which 16 studies including 8691 participants were included for NLR [15, 36, 41, 43-45, 50-59], 6 studies including 1113 participants for PLR $[15,36,50,54,60,61]$ and 9 studies including 3685 participants for PLT [17, 21, 29, 31, 36, 42, 51, 56, 59, 62].

The detail search process and summary of studies were showed in study flow diagram (Figure 1). The other study characteristics were showed in Table 1.

\section{The prognostic value of elevated NLR}

Of the 16 studies included for NLR, 13 studies including 4628 participants provided the available data for evaluating the association between NLR (cut-off $=5$ ) and OS, and 5 studies including 2178 participants for DFS. In addition, 3 studies $[15,43,53]$ including 4063 participants were included for evaluating the association between NLR (cut-off value $=3$ ) and OS.

As displayed in Figure 2, for association between NLR (cut-off value $=3$ ) and OS, meta-analysis showed no significant correlation, with the pooled HR being 1.19 [95\% CI $0.86-1.66 ; P=0.29]$. For the cut-off value of NLR equal to 5 , the pooled HR in patients with elevated NLR was significant higher than patients with normal NLR $[\mathrm{HR}=1.92,95 \%$ CI 1.57-2.34; $P<0.00001]$ (Figure 3). Significant results were also fund with the pooled analyses for the association between elevated NLR and DFS, with the pooled HR being 1.66 [95\% CI 1.31-2.11; $P<0.0001]$ (Figure 4).

\section{The prognostic value of elevated PLR}

Six studies reported the association between PLR (cut-off value $=150$ ) and prognosis, of which five studies including 956 participants were for OS and three studies $[15,50,60]$ including 471 participants were for DFS.

For PLR, as the significant heterogeneity between studies $\left(I^{2} \geq 50 \%, P \leq 0.05\right)$, a random effect model was used to estimate the pooled HR. The combined HR indicated that elevated PLR had a statistically significant association with the OS of patients with colorectal cancer $[\mathrm{HR}=1.56,95 \%$ CI 1.04-2.33; $P=0.03]$ (Figure 5). The pooled HR with numerical significant heterogeneity indicated that elevated PLT had no significant association with DFS $[\mathrm{HR}=1.49,95 \%$ CI $0.76-2.91 ; P=0.25]$ (Figure 6).

\section{The prognostic value of elevated PLT}

Nine studies including 3685 participants reported the association between elevated PLT and overall survival in patients with colorectal, with the cut-off value of platelet counts equal to $400 \times 10^{9} / \mathrm{L}$. As no significant heterogeneity between studies $\left(I^{2} \leq 50 \%\right.$ and $\left.P \geq 0.05\right)$, a fixed effect model was used to estimate the association between elevated PLT and OS. The pooled HR with no significant heterogeneity indicated that elevated PLT had an obvious association with overall survival $[\mathrm{HR}=1.89$, 95\% CI 1.58-2.25; $P<0.00001]$ (Figure 7).

\section{Publication bias}

Funnel plots were conducted for assessing the publication bias of included literatures and we could roughly assess the publication bias by seeing whether their shapes were of any obvious asymmetry. The funnel plots of NLR (cut-off value $=3$ ) for OS, NLR (cut-off value $=5$ ) for DFS and PLR did not reveal any obvious evidence of asymmetry (Figure 8A, 8C, 8D and Supplementary Figure 1). However, significant bias were found in both NLR (cut-off value $=5$ ) and PLT for OS (Figure 8B and Supplementary Figure 2) and the analysis of causes were offered in discussion.

\section{DISCUSSION AND CONCLUSIONS}

The relation between inflammation and malignancies was identified in the 19th century by Rudolf Virchow [63]. Growing evidences have support inflammation may play important roles in the development and progress of many inflammation, including CRC $[14,64,65]$. Many inflammatory cells and growth factors they produced could activate stroma and DNA-damagepromoting agents [66]. Meanwhile, tumors can increase inflammatory process and promote proliferation and metastases development of tumor cells by decreasing apoptosis and increasing angiogenesis and DNA damage in return [67].

Platelet plays an important role in the development and progression of malignancies as well. Great interest has been given in the prognostic role of thrombocytosis for patients with malignancies recently, as previously mentioned. However, the true mechanism or association between thrombocytosis and malignancies had not been clarified. There were several possible explanations for the association between elevated platelet counts and poor prognosis of malignancies. First, platelet might protect tumor cells from cytolysis, thereby promoting metastasis, by surface shielding them from immune system detection, 
and this seems to be the main mechanism of platelet protection [68]. Secondly, angiogenesis regulatory proteins are implicated in tumor growth and invasion. In colorectal cancer patients, the levels of PDGF, PF4 and VEGF are elevated in platelets, and the elevated levels of all three proteins correlated with the cancer state [69]. Platelets could stimulate angiogenic vessel growth and prevent hemorrhage from the angiogenic vessels, which was promoted by the adhesion function of platelet, as mediated by glycoprotein (GP) Ib $\alpha$, and these processes could stimulate and potentiate tumor cells to form distant metastases [70]. Additionally, T-factor could reveal that platelets may assist tumor cells in invading to adjacent tissues, and thrombocytosis is just right strongly correlated with the progression of T-factor.

We perform this meta-analysis for purpose of demonstrating the indicative significance of NLR, PLR and elevated platelet counts for prognosis in patients with colorectal cancer. Our results statistically supported the conclusions that elevated NLR or PLT had a significant association with the poor prognosis in colorectal cancer, which was consist with the conclusions in gastric cancer, lung cancer and gynecologic malignancies [6, 7, 9]. In addition, we also assessed the association between elevated PLR and prognosis, but no significance was found, for the pooled HR being 1.56 [95\% CI 1.04-2.33; $P=0.03$ ] for OS and 1.49 [95\% CI 0.76-2.91; $P=0.25]$ for DFS. By sensitivity analysis, we found that the study from Son, Z.Q 2014 had a significant impact for the results [50]. When the study was rejected from the analysis lists, the pooled HR became 1.86 [95\% CI 1.20-2.89; $P=0.006$ ] for OS and 1.93 [95\% CI 1.34-2.77; $P=0.0004$ ] for DFS. What is more, for the association between NLR (cut-off value $=3$ ) and OS, meta-analysis also showed no significant correlation, with the pooled HR being 1.19 [95\% CI 0.86-1.66; $P=0.29$ ]. Likewise, when the study from He, Wen-zhuo. 2013 [53] was rejected by sensitivity analysis, the pooled HR became 1.36 [95\% CI 1.05-1.75;

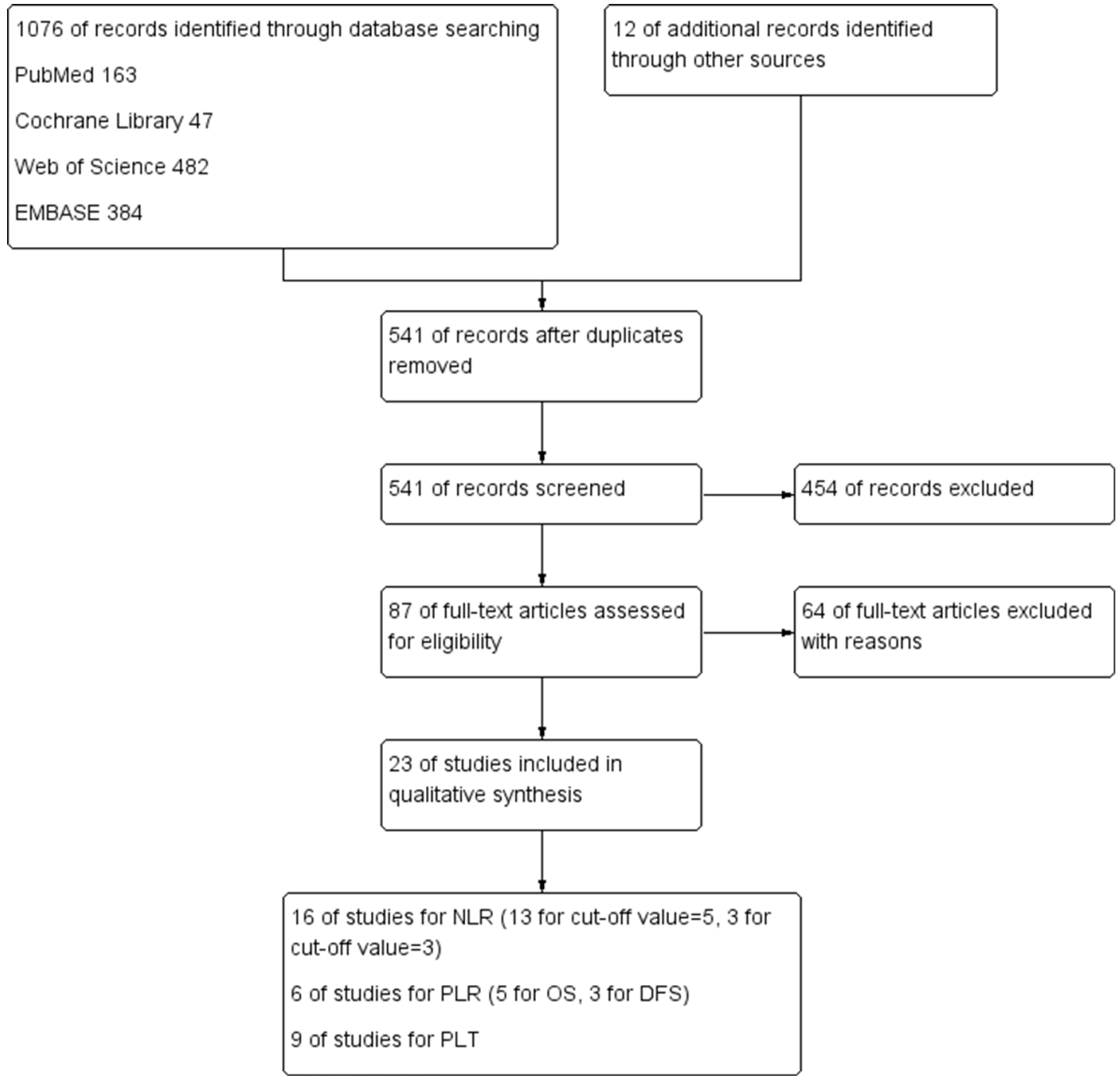

Figure 1: Flow diagram of the search strategy for pretreatment NLR, PLR and PLT as prognostic roles in patients with colorectal cancer. 


\begin{tabular}{|c|c|c|c|c|c|c|c|c|c|c|c|}
\hline Year & Author & Country & Study design & Cut-off value & $N$ & Clinical stage & $P$ value & Pretreatment & FT (month) & NOS score & Outcome \\
\hline \multicolumn{12}{|c|}{ The association between the prognosis and NLR in colorectal cancer patients: } \\
\hline 2015 & Neal CP. & UK & Pro & 5 & 302 & NR & NR & Sur & $29.7(4-96)$ & 6 & OS \\
\hline 2014 & Paik KY. & Korea & Pro & 5 & 600 & $\mathrm{I}-\mathrm{IV}$ & 0.402 & Radio & $27.4(1-72)$ & 8 & OS \\
\hline 2014 & Sun ZQ. & China & Pro & 5 & 225 & $\mathrm{I}-\mathrm{III}$ & 0.000 & Sur & NR & 6 & OS, DFS \\
\hline 2013 & Son HJ. & Korea & Retro & 5 & 624 & I - III & 0.001 & Sur & $42.0(1-66)$ & 7 & OS, DFS \\
\hline 2013 & Urrejola G. & Chile & Pro & 5 & 120 & II & - & Sur & $73.0(20-114)$ & 8 & OS \\
\hline 2012 & Carruthers R. & UK & Retro & 5 & 115 & NR & NR & CRT & 37.1 & 6 & OS, DFS \\
\hline 2012 & Kwon HC. & Korea & Pro & 5 & 200 & $\mathrm{I}-\mathrm{IV}$ & NR & Sur & NR & 6 & OS \\
\hline 2011 & Chua W. & Australia & Pro & 5 & 349 & NR & NR & Chemo & NR & 5 & OS \\
\hline 2011 & Hung HY. & Taiwan, & Pro & 5 & 1040 & $\mathrm{I}-\mathrm{II}$ & - & Sur & $74.5(45.9-136.8)$ & 7 & OS, DFS \\
\hline 2009 & Neal CP. & UK & Pro & 5 & 174 & NR & NR & Sur & NR & 7 & OS, DFS \\
\hline 2009 & Kishi Y. & US & Pro & 5 & 290 & NR & NR & Sur, Chemo & $28(2-102)$ & 8 & os \\
\hline 2008 & Halazun KJ. & UK & Retro & 5 & 440 & NR & NR & Sur & $24(11-97)$ & 6 & OS \\
\hline 2007 & Leitch EF. & UK & Pro & 5 & 149 & $I-I V$ & 0.001 & Sur & $48(36-73)$ & 8 & OS \\
\hline \multirow[t]{2}{*}{2012} & Chiang SF.(C) * & Taiwan,C & Retro & 3 & 1788 & $\mathrm{I}-\mathrm{III}$ & NR & Sur & $96.2(11.6-139.1)$ & 7 & OS \\
\hline & Chiang SF.(R)* & Taiwan,C & Retro & 3 & 1943 & $\mathrm{I}-\mathrm{III}$ & NR & Sur & $96.2(11.6-139.1)$ & 7 & OS \\
\hline 2013 & He W. & China & Pro & 3 & 243 & NR & NR & Chemo & 21.87 & 6 & os \\
\hline 2015 & Toiyama Y. & Japan & Pro & 3 & 89 & $\mathrm{I}-\mathrm{III}$ & NR & CRT & $56(2-147)$ & 7 & os \\
\hline \multicolumn{12}{|c|}{ The association between the prognosis and PLR in colorectal cancer patients: } \\
\hline 2015 & Neal CP. & UK & Pro & 150 & 302 & NR & NR & Sur & $29.7(4-96)$ & 6 & OS \\
\hline 2014 & Neofytou K. & UK & Retro & 150 & 140 & NR & NR & Chemo & $33(1-103)$ & 7 & OS \\
\hline 2014 & Sun ZQ. & China & Pro & 150 & 225 & $\mathrm{I}-\mathrm{III}$ & 0.000 & Sur & NR & 6 & OS, DFS \\
\hline 2015 & Toiyama Y. & Japan & Pro & 150 & 89 & $\mathrm{I}-\mathrm{III}$ & NR & CRT & $56(2-147)$ & 7 & OS, DFS \\
\hline 2015 & Mori K. & Japan & Retro & 150 & 157 & $\mathrm{I}-\mathrm{III}$ & 0.176 & Sur & $20.5(0.2-62.4)$ & 7 & DFS \\
\hline 2012 & Kwon HC. & Korea & Pro & 150 & 200 & $I-I V$ & NR & Sur & NR & 6 & OS \\
\hline \multicolumn{12}{|c|}{ The association between the prognosis and PLT in colorectal cancer patients: } \\
\hline 2015 & Josa V. & Hungary & Retro & $400 \times 109 / \mathrm{L}$ & 336 & $\mathrm{I}-\mathrm{IV}$ & NR & Sur & 46.0 & 6 & OS \\
\hline 2015 & Neal CP. & UK & Pro & $400 \times 109 / \mathrm{L}$ & 302 & NR & NR & Sur & $29.7(4-96)$ & 6 & OS \\
\hline 2014 & Paik KY & Korea & Pro & $400 \times 109 / \mathrm{L}$ & 600 & $\mathrm{I}-\mathrm{IV}$ & 0.402 & Radio & $27.4(1-72)$ & 8 & OS \\
\hline 2013 & Wan S. & USA & Retro & $400 \times 109 / \mathrm{L}$ & 1513 & $0-\mathrm{IV}$ & 0.0001 & Sur & $46.7(19.6-84.7)$ & 7 & OS \\
\hline 2010 & Qiu Mz. & China & Retro & $400 \times 109 / \mathrm{L}$ & 363 & $\mathrm{I}-\mathrm{IV}$ & 0.001 & NR & $26(3-50)$ & 6 & OS \\
\hline 2009 & Neal CP. & UK & Pro & $400 \times 109 / \mathrm{L}$ & 174 & NR & NR & Sur & NR & 7 & OS, DFS \\
\hline 2007 & Leitch EF. & UK & Pro & $400 \times 109 / \mathrm{L}$ & 149 & $\mathrm{I}-\mathrm{IV}$ & 0.001 & Sur & $48(36-73)$ & 8 & OS \\
\hline 2005 & Kandemir EG. & Turkey & Retro & $400 \times 109 / \mathrm{L}$ & 198 & NR & NR & Sur & $47(19-100)$ & 6 & OS \\
\hline 2012 & Kaneko M. & Japan & Retro & $400 \times 109 / \mathrm{L}$ & 50 & NR & NR & Chemo & $17.0(0.77-61.6)$ & 7 & OS, DFS \\
\hline
\end{tabular}

*They were from the same study; the former represented colon cancer marked with $\mathrm{C}$ and the latter represented rectal cancer marked with R. N: total number of eligible patients. NOS: Newcastle-Ottawa Scale. OS: overall survival. DFS: disease free survival. FT: follow-up time (month) (median and range). Chemo: chemotherapy. Radio: radiotherapy. CRT: chemo-radiation. Sur: surgery. Retro: retrospective. Pro: prospective. NR: not report.

$P=0.02]$. Another cause of the results may be the small number patients or only a few studies for the analyses. The sensitivity analysis did not draw any different conclusions for other analyses in this meta-analysis.

Nevertheless, there were several limitations for this meta-analysis. The main limitation is the inconsistency of the cut-off values of NLR, PLR and platelet counts. For NLR, some studies used the cut-off values with 4, 2.9, 2.8, and 2.6 and so on. For example, Shen, L.J [39] suggested that 2.8 was the best cut-off value of NLR for distinguishing the prognosis of patients with $\mathrm{CRC}$, differently from 4.0 in the study of Kaneko, M [42]. The cut-off values of PLR ranged from 150 to 300 . But many studies used 150 as the best cut-off value. The definition of thrombocytosis or elevated platelet counts ranged from $260 \times 10^{9} / \mathrm{L}$ to $400 \times 10^{9} / \mathrm{L}$. Based on the various discordance, we chose 5,150 and $400 \times 10^{9} / \mathrm{L}$ as the cut-off value of NLR, PLR and PLT respectively with decreasing the number of studies included. The second limitation is the variation of the clinical stages, for that the prognosis of patients with cancer is associated with clinical stages. The majority of studies included showed no significant difference in clinical stages with the $P$ value of Chi-squared test more than 0.05 . But there were many studies had significant differences in clinical stages for NLR [50, 52, 59], PLR [50] and platelet count $[21,29,59]$ with the $P$ value less than 0.05 . Besides, the incidence or significance of the association between different clinical stages and prognosis for PLT was also different. The incidence of thrombocytosis was associated with clinical stages and increased to $12.2 \%$ and $20.6 \%$ in patients with stage III and IV disease respectively [19]. As 2014 Guo, Tian-hua reported, thrombocytosis has association with poor prognostic significance in patients with stage I to stage III colorectal cancer, but not in patients with stage IV disease. In addition, Sasaki K suggested that preoperative thrombocytosis was an independent indicator only in patients at stage II for cancer-specific survival [25]. Moreover, the time of measuring neutrophils, lymphocytes and platelet count before treatment or surgery might be an important limiting factor. Blood samples of patients were obtained within 5-7 days before surgery in the study of Sun, Z.Q. [50], but 2 weeks prior to operation in Kazuhito 


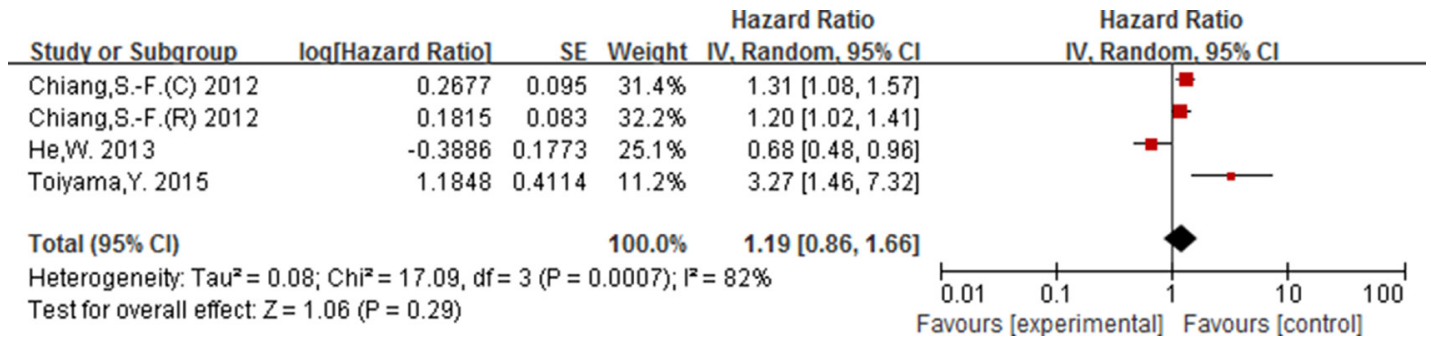

Figure 2: Forest plot of the prognostic effect of NLR (cut-off value $=3$ ) on overall survival.

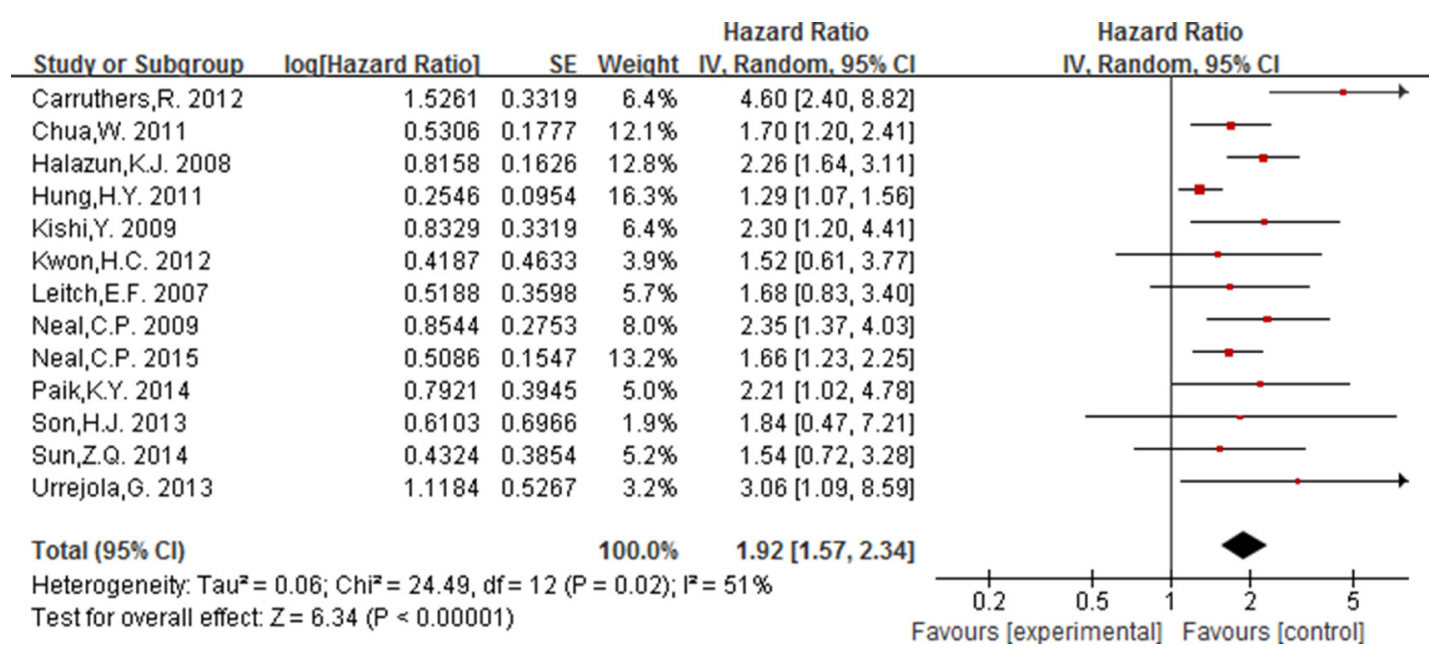

Figure 3: Forest plot of the prognostic effect of NLR (cut-off value $=5$ ) on overall survival.

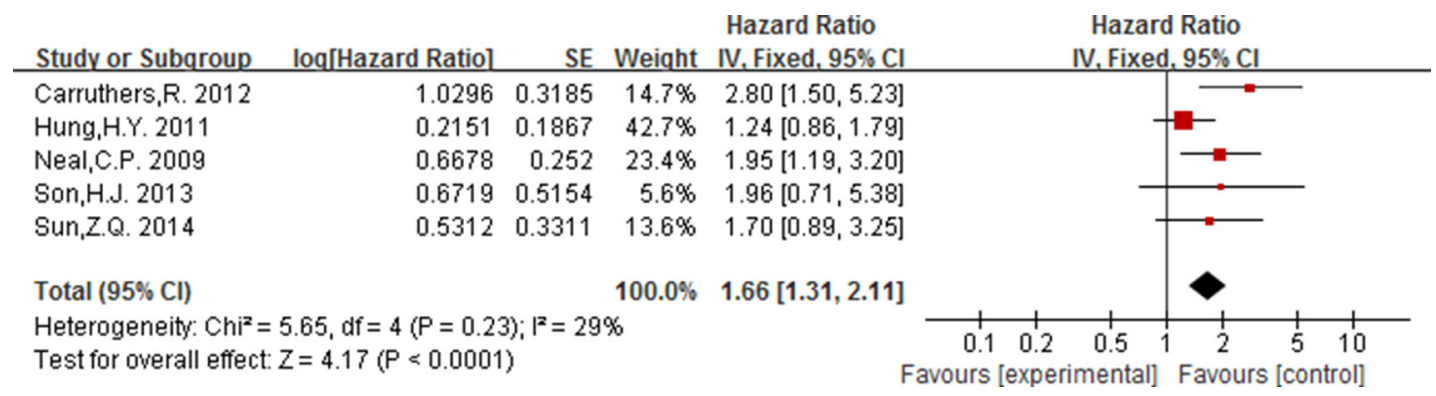

Figure 4: Forest plot of the prognostic effect of NLR (cut-off value $=5$ ) on disease free survival.

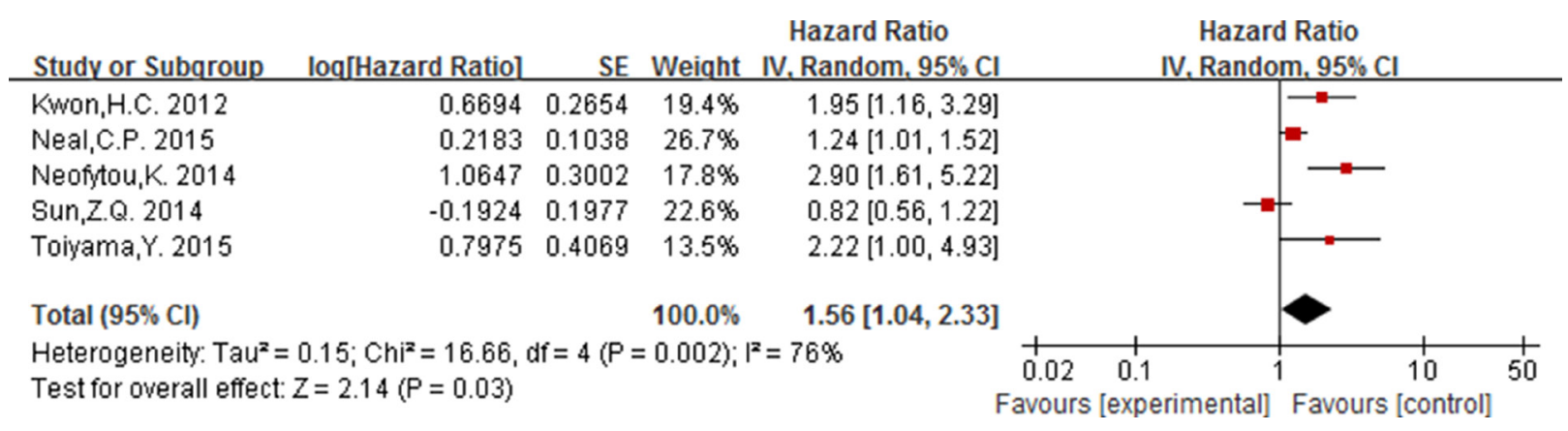

Figure 5: Forest plot of the prognostic effect of PLR (cut-off value $=150$ ) on overall survival. 


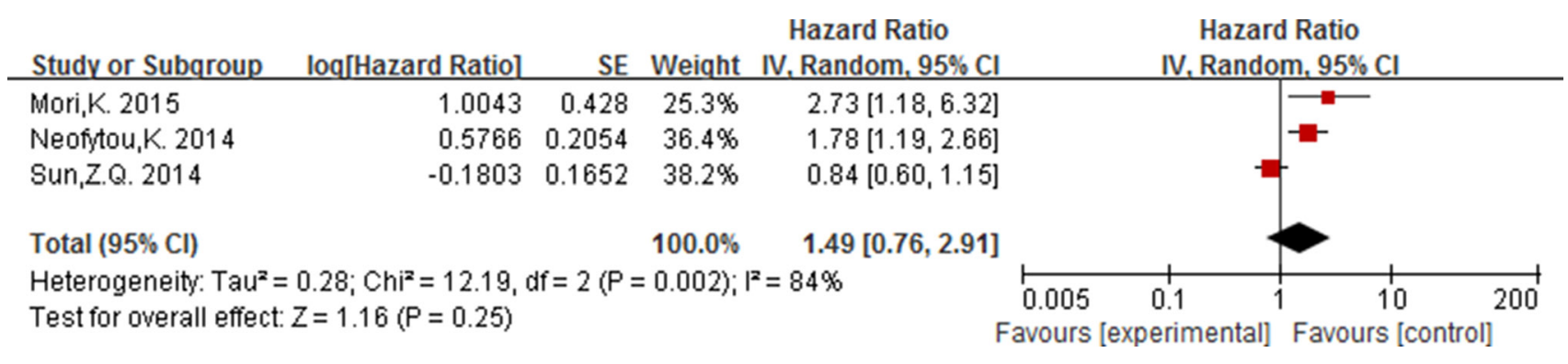

Figure 6: Forest plot of the prognostic effect of PLR (cut-off value $=150$ ) on disease free survival.

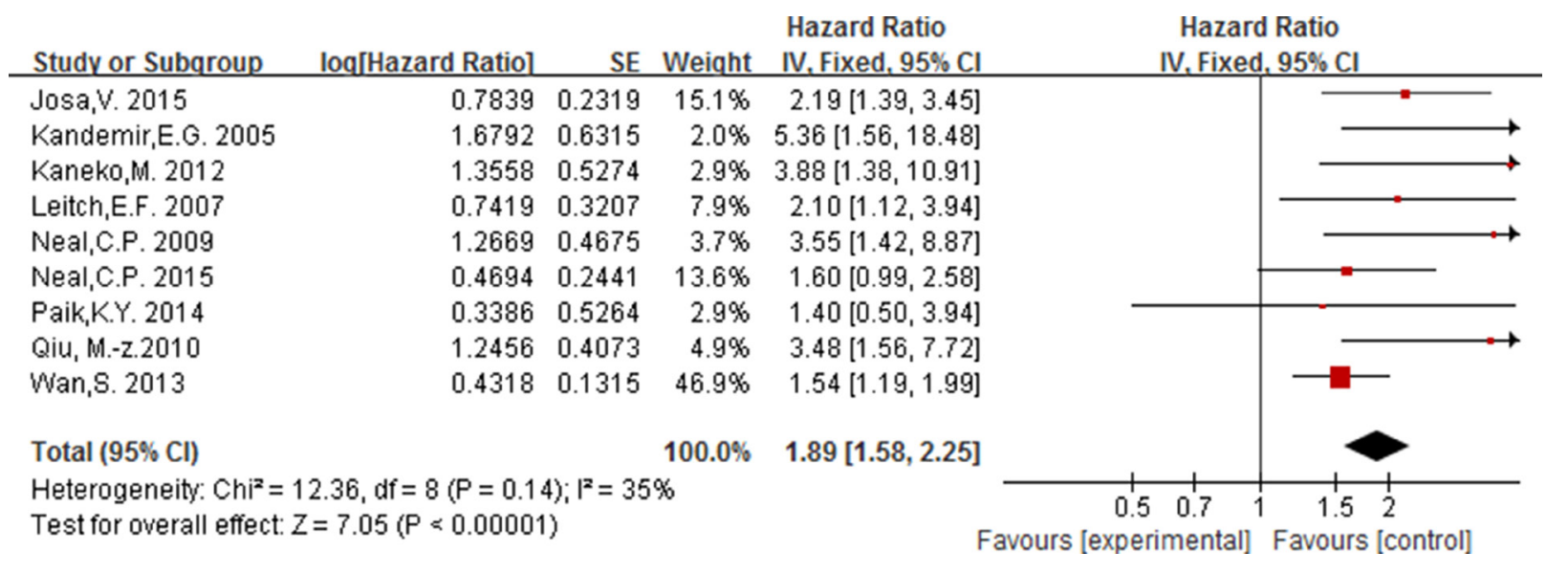

Figure 7: Forest plot of the prognostic effect of PLT (cut-off value $=400 \times 10^{9} / \mathrm{L}$ ) on overall.
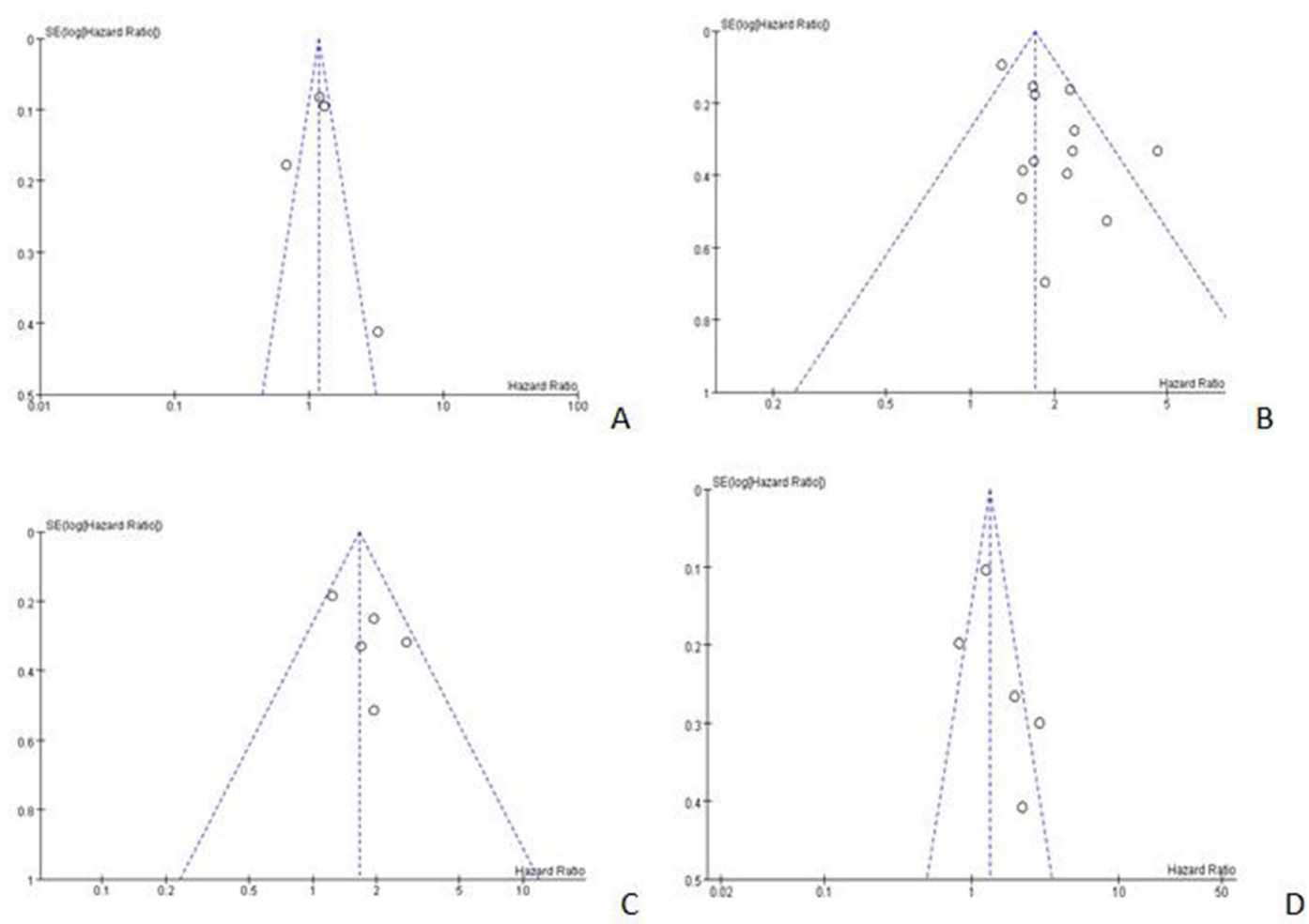

Figure 8: Begger's funnel plots for detecting publication bias. (A) NLR (cut-off value = 3) for OS; (B) NLR (cut-off value = 5) for OS; (C) NLR (cut-off value = 5) for DFS; (D) PLR (cut-off value = 150) for OS. 
Sasaki [25]. Finally, the prognosis or the value of neutrophils, lymphocytes and platelet count were also influenced by other multiple factors, such as age, adjuvant therapy, and tumor size, histological type, venous involvement, which should also be taken into consideration. The last important limitation was the publication bias. As mentioned before, there were obvious bias in both NLR (cut-off value $=5$ ) and PLT for OS and the analysis of causes were offered in discussion. The factors impacting publication bias may be various. In my opinion, apart from the factors like no publication of negative results, termination of publication, the language limitation may be the main influence, for that our searching language was only English.

Taking the limitations above into account, further researches need to clear the association between elevated NLR, PLR and platelet counts and prognosis in patients with different clinical stages.

Despite many difference and influencing factors, we could cautiously draw a conclusion that elevated NLR, PLR and platelet counts may have a close association with worse survival in colorectal cancer patients, with consideration of the evident statistical significance. Elevated NLR, PLR and platelet counts may be used as three prognostic indicators for early identification of CRC patients with worse prognosis, and then more attention and adjuvant therapy could be given to these patients.

\section{MATERIALS AND METHODS}

\section{Including and excluding criteria}

The including criteria of this meta-analysis were as follows: (1) All of randomized, controlled trials (RCTs), observational prospective or retrospective studies were included; (2) Included people with a diagnosis of colorectal cancer; (3) Included patients received operation or other adjuvant therapy; (4) Pretreatment platelet counts (cut-off value $=400 \times 10^{9} / \mathrm{L}$ ), NLR (cut-off value $=5$ ) or PLR (cutoff value $=150$ ) were reported or can be obtained; $(5)$ The outcomes including OS or DFS were reported; (6) Sufficient data (HR and 95\%CI on OS or DFS) were provided.

Excluding criteria were as follows: (1) Trials on animals; (2) Abstracts, letters, editorials, expert opinions, reviews, case reports; (3) Patients having other primary tumors; (4) Studies without sufficient data; (5) The cut-off value did not meet our including criteria.

\section{Search strategy}

We searched PubMed, EMBASE, Cochrane Library and Web of Science to April, 2015. We also hand searched the citation lists of included studies and previously identified systematic reviews to identify further relevant trials. our searching terms and procedures were as follows: (1)"thrombocytosis", "platelet count*"; (2) "neutrophil lymphocyte ratio"; "neutrophil to lymphocyte ratio", NLR; (3) "platelet lymphocyte ratio", "platelet to lymphocyte ratio", PLR; (4) "colorectal cancer", "rectal cancer", "colonic cancer"; (5) "prognosis", "survival", "outcome"; (1 OR 2 OR 3) AND 4 AND 5. Other related terms, including references of some literatures we read, were also searched in English. Two assessors independently screened the titles and abstracts of each study. Once relevant studies became certain, the full texts were obtained for further evaluation.

\section{Quality assessment}

Two reviewers assessed the quality of all the included studies using the 9-star Newcastle-Ottawa Scale (NOS) [71] independently, and the total scores of each study were displayed in the characteristics table. The scores were judged according to the three aspects of NOS of evaluation: selection, comparability, and outcome between the case group and control group. Studies with the scores $\geq 6$ were assigned as high-quality studies.

\section{Data extraction}

Data for the analysis were extracted independently by two reviewers, and disagreement was resolved by their discussion. In addition, the extracted contents including study demographics, published years, country, trial design, outcome and clinical stage were extracted using a standardized form.

Data collected were input into RevMan 5.2 software for analysis [72].

\section{Statistical analysis}

In this meta-analysis, the impact of NLR, PLR or PLT on patients' prognosis was measured by estimating the Hazard Ratio (HR) between elevated NLR, PLR or PLT groups and normal NLR, PLR or PLT groups. The associated 95\% confidence intervals (CI) were also measured. The heterogeneity between studies was evaluated with $P$ value and $I^{2} . I^{2} \geq 50 \%$ or $P \leq 0.05$ was deemed to represent significant heterogeneity [73, 74], and pooled HR was estimated using a Random-effect model. On the contrary, if statistical study heterogeneity was not observed $\left(\mathrm{I}^{2} \leq 50 \%\right.$ and $\left.P \geq 0.05\right)$, a fixed effects model was used. Finally, publication bias was assessed by Begg's and Egger's test. If the shape of funnel plots revealed no obvious evidence of asymmetry, we considered that there was no obvious publication bias. All statistical analyses were performed using standard statistical procedures provided in RevMan 5.2 [73].

\section{ACKNOWLEDGMENTS AND FUNDING}

We are grateful for contributions from all the group members including the following individuals: Jie Zhang, Hong-Ying Zhang and Jia Li contributed to the study design, data analysis and quality assessment. Xin-Yu Shao, Jie Zhang and Chun-Xia Zhang contributed to the literature search. There is no funding for this work. 


\section{CONFLICTS OF INTEREST}

The authors declare no interest.

\section{REFERENCES}

1. Ferlay J, Soerjomataram I, Dikshit R, Eser S, Mathers C, Rebelo M, Parkin DM, Forman D, Bra F. Cancer incidence and mortality worldwide: Sources, methods and major patterns in GLOBOCAN 2012. International Journal of Cancer. 2015; 136:E359-E386.

2. Kanavos P, Schurer W. The dynamics of colorectal cancer management in 17 countries. European Journal of Health Economics. 2010; 10:115-129.

3. Canadian Cancer Society's Advisory Committee on Cancer Statistics (2013) Canadian Cancer Statistics 2013. http:// www.cancer.ca//media/cancer.ca/CW/cancer\%20information/ cancer\%20101/Canadian\%20cancer\%20tatistics/canadiancancer- statistics-2013-EN.pdf. Accessed 10 Sept 2013.

4. Aranda E, Aparicio J, Alonso V, Garcia-Albeniz X, GarciaAlfonso P, Salazar R, Valladares M, Vera R, Vieitez JM, Garcia-Carbonero R. SEOM clinical guidelines for diagnosis and treatment of metastatic colorectal cancer 2015. Clinical \& Translational Oncology. 2015; 17:972-981.

5. National Cancer Institute (2011) SEER Stat Fact Sheets: Colon and Rectum Cancer. http://seer.cancer.gov/statfacts/ html/colorect.html. Accessed 12 Aug 2014.

6. Xin-Ji Z, Yong-Gang L, Xiao-Jun S, Xiao-Wu C, Dong $\mathrm{Z}$, Da-Jian Z. The prognostic role of neutrophils to lymphocytes ratio and platelet count in gastric cancer: A meta-analysis. International Journal of Surgery. 2015; 21:84-91.

7. Zhang X, Ran Y. Prognostic role of elevated platelet count in patients with lung cancer: a systematic review and metaanalysis. International Journal of Clinical and Experimental Medicine. 2015; 8:5379-5387.

8. Men H, Liang C, Yu M. Thrombocytosis as a prognostic factor in patients with renal cell carcinoma: A meta-analysis of literature. Journal of Cancer Research and Therapeutics. 2015; 11:67-72.

9. Yu M, Liu L, Zhang BL, Chen Q, Ma XL, Wu YK, Liang CS, Niu ZM, Qin X, Niu T. Pretreatment Thrombocytosis as a Prognostic Factor in Women with Gynecologic Malignancies: a Meta-analysis. Asian Pacific Journal of Cancer Prevention. 2012; 13:6077-6081.

10. Lai Q, Castro Santa E, Rico Juri JM, Pinheiro RS, Lerut J. Neutrophil and platelet-to-lymphocyte ratio as new predictors of dropout and recurrence after liver transplantation for hepatocellular cancer. Transplant International. 2014; 27:32-41.

11. Feng JF, Huang Y, Chen QX, Preoperative platelet lymphocyte ratio (PLR) is superior to neutrophil lymphocyte ratio (NLR)as a predictive factor in patients with esophageal squamous cell carcinoma. World Journal of Surgical Oncology. 2014; 12.
12. Feng JF, Huang Y, Zhao Q, Chen QX. Clinical significance of preoperative neutrophil lymphocyte ratio versus platelet lymphocyte ratio in patients with small cell carcinoma of the esophagus. The Scientific World Journal. 2013; 2013:504365.

13. Wosnitzer M, Polland A, Hai Q, Hruby G, McKiernan J. Role of preoperative platelet level in clinical and pathological outcomes after surgery for renal cortical malignancies. Bju International. 2011; 108:73-79.

14. Symbas NP, Townsend MF, El-Galley R, Keane TE, Graham SD, Petros JA. Poor prognosis associated with thrombocytosis in patients with renal cell carcinoma. Bju International. 2000; 86:203-207.

15. Toiyama $Y$, Inoue $Y$, Kawamura M, Kawamoto A, Okugawa Y, Hiro J, Saigusa S, Tanaka K, Mohri Y, Kusunoki M. Elevated Platelet Count as Predictor of Recurrence in Rectal Cancer Patients Undergoing Preoperative Chemoradiotherapy Followed by Surgery. International Surgery. 2015; 100:199-207.

16. Josa V, Krzystanek M, Vass T, Lang T, Juhász V, Szilágyi K, Tihanyi B, Harsányi L, Szállási Z, Salamon F, Baranyai Z. Thrombocytosis of Liver Metastasis from Colorectal Cancer as Predictive Factor. Pathology \& Oncology Research. 2015; 21:991-997.

17. Josa V, Krzystanek M, Eklund AC, Salamon F, Zarand A, Szallasi Z, Baranyai Z. Relationship of postoperative thrombocytosis and survival of patients with colorectal cancer. International Journal of Surgery. 2015; 18:1-6.

18. Al-Saeed EF, Tunio MA, Al-Obaid O, Abdulla M, Al-Anazi A, AlShenaifi JY, Al-Ameer L, Al-Obaidan T. Correlation of Pretreatment Hemoglobin and Platelet Counts with Clinicopathological Features in Colorectal Cancer in Saudi Population. Saudi Journal of Gastroenterology. 2014; 20:134-1388.

19. Guo T, Krzystanek M, Szallasi Z, Szallasi A. Thrombocytosis portends adverse prognostic significance in patients with stage II colorectal carcinoma. F1000Research. 2014; 3:180-180.

20. Baranyai Z, Krzystanek M, Jósa V, Dede K, Agoston E, Szász AM, Sinkó D, Szarvas V, Salamon F, Eklund AC, Szállási Z, Jakab F. The comparison of thrombocytosis and platelet-lymphocyte ratio as potential prognostic markers in colorectal cancer. Thrombosis and Haemostasis. 2014; 111:483-490.

21. Wan S, Lai Y, Myers RE, Li B, Hyslop T, London J, Chatterjee D, Palazzo JP, Burkart AL, Zhang K, Xing J, Yang H. Preoperative platelet count associates with survival and distant metastasis in surgically resected colorectal cancer patients. Journal of gastrointestinal cancer. 2013; 44:293-304.

22. Kawai K, Kitayama J, Tsuno NH, Sunami E, Watanabe T. Thrombocytosis before pre-operative chemoradiotherapy predicts poor response and shorter local recurrence-free survival in rectal cancer. International Journal of Colorectal Disease. 2013; 28:527-535. 
23. Juan Castillo-Perez J. Regarding the Article "Thrombocytosis As a Predictor of Distant Recurrence in Patients with Rectal Cancer". Archives of Medical Research. 2013; 44:77-78.

24. Ishizuka M, Nagata H, Takagi K, Iwasaki Y, Kubota K. Combination of platelet count and neutrophil to lymphocyte ratio is a useful predictor of postoperative survival in patients with colorectal cancer. British Journal of Cancer. 2013; 109:401-407.

25. Sasaki K, Kawai K, Tsuno NH, Sunami E, Kitayama J. Impact of Preoperative Thrombocytosis on the Survival of Patients with Primary Colorectal Cancer. World Journal of Surgery. 2012; 36:192-200.

26. Lin MS, Huang JX, Zhu J, Shen HZ. Elevation of Platelet Count in Patients with Colorectal Cancer Predicts Tendency to Metastases and Poor Prognosis. HepatoGastroenterology. 2012; 59:1687-1690.

27. Ishizuka M, Nagata H, Takagi K, Iwasaki Y, Kubota K. Preoperative thrombocytosis is associated with survival after surgery for colorectal cancer. Journal of Surgical Oncology. 2012; 106:887-891.

28. Cravioto-Villanueva A, Luna-Perez P, Gutierrez-de la Barrera M, Martinez-Gómez H, Maffuz A, Rojas-Garcia P, Perez-Alvarez C, Rodriguez-Ramirez S, RodriguezAntezana E, Ramirez-Ramirez L. Thrombocytosis as a Predictor of Distant Recurrence in Patients with Rectal Cancer. Archives of Medical Research. 2012; 43:305-311.

29. Qiu MZ, Yuan ZY, Luo HY, Ruan DY, Wang ZQ, Wang FH, $\mathrm{Li} \mathrm{YH,} \mathrm{Xu} \mathrm{RH.} \mathrm{Impact} \mathrm{of} \mathrm{pretreatment} \mathrm{hematologic} \mathrm{profile}$ on survival of colorectal cancer patients. Tumor Biology. 2010; 31:255-260.

30. Nyasavajjala SM, Runau F, Datta S, Annette H, Shaw AG, Lund JN. Is there a role for pre-operative thrombocytosis in the management of colorectal cancer? International Journal of Surgery. 2010; 8:436-438.

31. Kandemir EG, Mayadagli A, Karagoz B, Bilgi O, Turken O, Yaylaci M. Prognostic significance of thrombocytosis in node-negative colon cancer. Journal of International Medical Research. 2005; 33:228-235.

32. Shwaiki A, Safar AM. The impact of platelet count (Plt\#) on outcome in curable colon cancer. Journal of Clinical Oncology. 2004; 22:893S-893S.

33. Padilla D, Cubo T, Pardo R, Molina JM, Martín J, Hernández J. Preoperative platelet count and colorectal cancer recurrence. [Article in Spanish]. Revista Espanola De Enfermedades Digestivas. 2004; 96:733-734.

34. Monreal M, Fernandez-Llamazares J, Piñol M, Julian JF, Broggi M, Escola D, Abad A. Platelet count and survival in patients with colorectal cancer - a preliminary study. Thrombosis and Haemostasis. 1998; 79:916-918.

35. Zou ZY, Liu HL, Ning N, Li SY, DU XH, Li R. Clinical significance of pre-operative neutrophil lymphocyte ratio and platelet lymphocyte ratio as prognostic factors for patients with colorectal cancer. Oncology Letters. 2016; $11: 2241-2248$.
36. Neal CP, Cairns V, Jones MJ, Masood MM, Nana GR, Mann CD, Garcea G, Dennison AR. Prognostic performance of inflammation-based prognostic indices in patients with resectable colorectal liver metastases. Medical Oncology. $2015 ; 32$.

37. Choi WJ, Cleghorn MC, Jiang H, Jackson TD, Okrainec A, Quereshy FA. Preoperative Neutrophil-to-Lymphocyte Ratio is a Better Prognostic Serum Biomarker than Plateletto-Lymphocyte Ratio in Patients Undergoing Resection for Nonmetastatic Colorectal Cancer. Annals of Surgical Oncology. 2015; 22:S603-S613.

38. Ying HQ, Deng QW, He BS, Pan YQ, Wang F, Sun HL, Chen J, Liu X, Wang SK. The prognostic value of preoperative NLR, d-NLR, PLR and LMR for predicting clinical outcome in surgical colorectal cancer patients. Medical oncology. 2014; 31:305.

39. Shen LJ, Zhang H, Liang L, Li G, Fan M, Wu Y, Zhu J, Zhang Z. Baseline neutrophil-lymphocyte ratio $(>=2.8)$ as a prognostic factor for patients with locally advanced rectal cancer undergoing neoadjuvant chemoradiation. Radiation Oncology. 2014; 9.

40. Azab B, Mohammad F, Shah N, Vonfrolio S, Lu W, Kedia $\mathrm{S}$, Bloom SW. The value of the pretreatment neutrophil lymphocyte ratio vs. platelet lymphocyte ratio in predicting the long-term survival in colorectal cancer. Cancer Biomarkers. 2014; 14:303-312.

41. Urrejola GI, Bambs CE, Espinoza MA, Gellona J, Zúñiga AM, Molina ME, Bellolio F, Miguieles R, Campbell JM, Pinedo GA. An elevated neutrophil/lymphocyte ratio is associated with poor prognosis in stage II resected colon cancer. [Aticle in Spanish]. Revista Medica De Chile. 2013; 141:602-608.

42. Kaneko M, Nozawa H, Sasaki K, Hongo K, Hiyoshi M, Tada N, Murono K, Nirei T, Kawai K, Sunami E, Tsuno NH, Kitayama J. Elevated Neutrophil to Lymphocyte Ratio Predicts Poor Prognosis in Advanced Colorectal Cancer Patients Receiving Oxaliplatin-Based Chemotherapy. Oncology. 2012; 82:261-268.

43. Chiang SF, Hung HY, Tang R, Changchien CR, Chen JS, You YT, Chiang JM, Lin JR. Can neutrophil-to-lymphocyte ratio predict the survival of colorectal cancer patients who have received curative surgery electively? International Journal of Colorectal Disease. 2012; 27:1347-1357.

44. Hung HY, Chen JS, Yeh CY, Changchien CR, Tang R, Hsieh PS, Tasi WS, You JF, You YT, Fan CW, Wang JY, Chiang JM. Effect of preoperative neutrophil-lymphocyte ratio on the surgical outcomes of stage II colon cancer patients who do not receive adjuvant chemotherapy. Int J Colorectal Dis. 2011; 26:1059-65.

45. Chua W, Charles KA, Baracos VE, Clarke SJ. Neutrophil/ lymphocyte ratio predicts chemotherapy outcomes in patients with advanced colorectal cancer. British Journal of Cancer. 2011; 104:1288-1295.

46. Oh SY, Lee YS, Suh KW. Preoperative thrombocytosis is a prognostic factor for patients with stage II colorectal cancer. Colorectal Disease. 2015; 17:77. 
47. Trebol J. Platelet count changes during colorectal cancer course: a potrntial novel diagnostic and prognostic tool. Diseases of the Colon \& Rectum. 2013; 56:E251-E252.

48. Ishizuka M, Kubota K. Clinical utility of inflammationbased prognostic systems in patients with colorectal cancer. Colorectal Cancer. 2013; 2:309-320.

49. Yu I, Chen L, Ruan JY, Chang JT, Cheung WY. Risk and management of venous thromboembolisms in bevacizumabtreated metastatic colorectal cancer patients. Supportive Care in Cancer. 2016; 24:1199-1208.

50. Sun ZQ, Han XN, Wang HJ, Tang Y, Zhao ZL, Qu YL, Xu RW, Liu YY, Yu XB. Prognostic significance of preoperative fibrinogen in patients with colon cancer. World Journal of Gastroenterology. 2014; 20:8583-8591.

51. Paik KY, Lee IK, Lee YS, Sung NY, Kwon TS. Clinical Implications of Systemic Inflammatory Response Markers as Independent Prognostic Factors in Colorectal Cancer Patients. Cancer Research and Treatment. 2014; 46:65-73.

52. Son HJ, Park JW, Chang HJ, Kim DY, Kim BC, Kim SY, Park SC, Choi HS, Oh JH. Preoperative Plasma Hyperfibrinogenemia is Predictive of Poor Prognosis in Patients with Nonmetastatic Colon Cancer. Annals of Surgical Oncology. 2013; 20:2908-2913.

53. He W, Yin C, Guo G, Jiang C, Wang F, Qiu H, Chen X, Rong R, Zhang B, Xia L. Initial neutrophil lymphocyte ratio is superior to platelet lymphocyte ratio as an adverse prognostic and predictive factor in metastatic colorectal cancer. Medical Oncology. 2013; 30.

54. Kwon HC, Kim SH, Oh SY, Lee S, Lee JH, Choi HJ, Park KJ, Roh MS, Kim SG, Kim HJ, Lee JH. Clinical significance of preoperative neutrophil-lymphocyte versus platelet-lymphocyte ratio in patients with operable colorectal cancer. Biomarkers. 2012; 17:216-222.

55. Carruthers R, Tho LM, Brown J, Kakumanu S, McCartney $\mathrm{E}, \mathrm{McDonald}$ AC. Systemic inflammatory response is a predictor of outcome in patients undergoing preoperative chemoradiation for locally advanced rectal cancer. Colorectal Disease. 2012. 14:E701-E707.

56. Neal CP, Mann CD, Sutton CD, Garcea G, Ong SL, Steward WP, Dennison AR, Berry DP. Evaluation of the prognostic value of systemic inflammation and socioeconomic deprivation in patients with resectable colorectal liver metastases. European Journal of Cancer. 2009; 45:56-64.

57. Kishi Y, Kopetz S, Chun YS, Palavecino M, Abdalla EK, Vauthey JN. Blood neutrophil-to-lymphocyte ratio predicts survival in patients with colorectal liver metastases treated with systemic chemotherapy. Annals of Surgical Oncology. 2009; 16:614-22.

58. Halazun KJ, Aldoori A, Malik HZ, Al-Mukhtar A, Prasad KR, Toogood GJ, Lodge JP. Elevated preoperative neutrophil to lymphocyte ratio predicts survival following hepatic resection for colorectal liver metastases. European journal of surgical oncology. 2008; 34:55-60.

59. Leitch EF, Chakrabarti M, Crozier JE, McKee RF, Anderson JH, Horgan PG, McMillan DC. Comparison of the prognostic value of selected markers of the systemic inflammatory response in patients with colorectal cancer. British Journal of Cancer. 2007; 97:1266-1270.

60. Mori K, Toiyama Y, Saigusa S, Fujikawa H, Hiro J, Kobayashi M, Ohi M, Araki T, Inoue Y, Tanaka K, Mohri Y, Kusunoki M. Systemic Analysis of Predictive Biomarkers for Recurrence in Colorectal Cancer Patients Treated with Curative Surgery. Digestive Diseases and Sciences. 2015; 60:2477-2487.

61. Neofytou K, Smyth EC, Giakoustidis A, Khan AZ, Cunningham D, Mudan S. Elevated platelet to lymphocyte ratio predicts poor prognosis after hepatectomy for liveronly colorectal metastases, and it is superior to neutrophil to lymphocyte ratio as an adverse prognostic factor. Medical Oncology. 2014; 31.

62. Baranyai Z, Jósa V, Krzystanek M, Eklund AC, Szász AM, Szállási Z. Evaluation of thrombocytosis as predictive factor in colorectal cancer. Magy Seb. 2013; 66:331-7.

63. Balkwill F, Mantovani A. Inflammation and cancer: back to Virchow? Lancet. 2001; 357:539-545.

64. Mantovani A, Sica A, Balkwill F. Cancer-related inflammation. Nature. 2008; 454:436-44.

65. Itzkowitz SH. Inflammation and cancer IV Colorectal cancer in inflammatory bowel disease: the role of inflammation. American journal of physiology-gastrointestinal and liver physiology. 2004; 287:G7-17.

66. Coussens LM, Werb Z. Inflammation and cancer. Nature. 2002; 420:860-867.

67. Grivennikov SI, Greten FR, Karin M. Immunity, inflammation, and cancer. Cell. 2010; 140:883-899.

68. Nieswandt B, Hafner M, Echtenacher B, Mannel DN. Lysis of tumor cells by natural killer cells in mice is impeded by platelets. Cancer Research. 1999; 59:1295-1300.

69. Peterson JE, Zurakowski D, Italiano JE Jr, Michel LV, Connors S, Oenick M, D'Amato RJ, Klement GL, Folkman J. VEGF, PF4 and PDGF are elevated in platelets of colorectal cancer patients. Angiogenesis. 2012; 15:265-273.

70. Kisucka J, Butterfield CE, Duda DG, Eichenberger SC, Saffaripour S, Ware J, Ruggeri ZM, Jain RK, Folkman J, Wagner DD. Platelets and platelet adhesion support angiogenesis while preventing excessive hemorrhage. Proc Natl Acad Sci USA. 2006; 103:855-860.

71. Wells GA, O'Connell BS. The Newcastle-Ottawa Scale (NOS) for Assessing the Quality of Nonrandomized Studies in Meta-analysis, Department of Epidemiology and Community Medicine, University of Ottawa, Canada, 2010.

72. Review Manager (RevMan) [Computer Program]. Version 5.2. Copenhagen: The Nordic Cochrane Centre, The Cochrane Collaboration, 2012.

73. Higgins J, GS (eds). Cochrane Handbook for Systematic Reviews of Interventions. Version 5.1.0 [updated March 2011]. The Cochrane Collaboration 2011. www.cochranehandbook.org (18 March 2014, date last accessed).

74. University of York Centre for Reviews and Dissemination. Systematic Reviews: CRD's Guidance for Undertaking Reviews in Health Care. York: CRD, University of York, 2009. 